\title{
Improving Native Hawaiian Health Through Community-Based Participatory Research
}

\author{
Megan Fong ${ }^{1,2}$, Kathryn L. Braun ${ }^{1,2}$, JoAnn Umilani Tsark ${ }^{1}$ \\ 1 'Imi Hale-Native Hawaiian Cancer Awareness, Research and Training Network, Papa Ola Lokahi \\ ${ }^{2}$ Center on Aging, John A. Burns School of Medicine, University of Hawai'i at Manoa
}

\begin{abstract}
Native Hawaiians, representing $20 \%$ of Hawai'i’s population, have higher mortality rates and lower life expectancy than all other ethnic groups in Hawai'i and most ethnic groups in the United States. Although research is needed to reduce health disparities, past research abuses have led to feelings of distrust among many Native Hawaiians toward traditionally conducted research. 'Imi Hale-Native Hawaiian Cancer Awareness, Research and Training Network was established in 2000, one of 18 Special Population Networks funded by the National Cancer Institute (NCI), to build a sustainable infrastructure for cancer prevention and control based on principles of community-based participatory research (CBPR). These principles give community members a voice in directing research and provide opportunities for community members to gain from research projects. This paper describes the major structures and mechanisms established by 'Imi Hale to assure community involvement and benefit. We also provide examples of how Native Hawaiians have impacted the design and conduct of specific research projects and how individuals and communities have benefited. 'Imi Hale advisors regularly complete a survey to gauge adherence to CBPR principles, and results from the 2002 survey are presented. The findings suggest that adhering to CBPR principles presents challenges to researchers, but that this approach is well received by the Native Hawaiians involved with 'Imi Hale, many of whom have seen positive benefits for themselves and their communities.
\end{abstract}

(C) 2003 Californian Journal of Health Promotion. All rights reserved.

Keywords: Cancer, guideline adherence, organizational case studies, Pacific Islander Americans, research ethics

\section{Introduction}

Although residents of Hawai'i are reputed to have the longest life span and the best health status in the nation, dramatic ethnic variation exists. Native Hawaiians, whose ancestors lived in the islands of Hawai'i prior to Western contact in 1778 , comprise about $20 \%$ of the state's population, and this group has the lowest life expectancy and the worst health indicators of the major ethnic groups in the state (Blaisdell, 1993; Braun, Yang, Onaka, \& Horiuchi, 1996; Chen, 1993; Santos et al., 2001). Nationally, Native Hawaiians have the highest mortality rates due to cardiovascular disease compared to all ethnic groups in the United State (U.S.), and they rank second in rates of obesity (Chen, 1993; William \& Collins, 1995). Native Hawaiian cancer mortality rates among men are second highest (African American men have the highest rates) and rates among Native Hawaiian women are tied for second highest with African American women (Alaska Native women have the highest rates) (Miller et al., 1996).

The disparity in health indicators and outcomes between Native Hawaiians and other Americans is influenced by a variety of factors. Previous research implicates both socioeconomic status (SES) and race as predictors of variations in health outcomes, illness, and death (William \& Collins, 1995). Although SES and race are correlated, with race generally used as a proxy for SES, it is unclear how SES and race are causally linked to health outcomes. However, research has found that, compared to high SES groups, low SES groups have less accessibility 
to quality health care, poorer health behaviors, worse working conditions, more environmental exposure, worse early life conditions, and less money and power, and these factors certainly affect health (Israel et al., 2001; Williams \& Collins, 1995). For Native Hawaiians, who have the lowest mean income, the highest rates of poverty and public assistance, and the worst health indicators of the major ethnic groups in Hawai'i (Blaisdell, 1993), the association between race, SES, and health status may be meaningful. The effects of racism may also influence health outcomes, especially by producing intermediate determinants of poor health (Jones, 2000; 2001; Williams \& Collins, 1995). For example, racism occurring on an institutional level can result in differential access to medical facilities, employment, sound housing, and a clean environment. Personally mediated racism, incorporating prejudicial and discriminatory acts, can result in poor service, avoidance, and dehumanization. Finally, internalized racism, in which members of a stigmatized race accept racist messages, can result in self-devaluation through engaging in risky health behaviors, coupled with helplessness and hopelessness (Jones, 2000; 2001). The health status of Native Hawaiians, who have experienced a loss of land and power and several centuries of disenfranchisement and discrimination within their traditional homeland, may be affected by racism, especially internalized racism, as evidenced by their fatalistic attitudes toward illness and death (Blaisdell, 1993; 1998; Braun, Look, \& Tsark, 1995; Gotay, Muraoka, \& Holup, 2001).

Although studies suggest several hypotheses and factors that contribute to racial disparities in health outcomes, little change has been effected to remedy the situation, and several studies suggest that inequalities are increasing (Israel, Schulz, Parker, \& Becker, 1998; Israel et al., 2001; Williams \& Collins, 1995). Public health research, especially prevention research, can be a powerful tool in identifying risk factors and formulating interventions, however it has been sparse and ineffective in several minority communities, including the Native Hawaiian community.
Most modern research embodies the traditional positivist paradigm, in which the researcher is an expert, distant and value-free, existing only to discover a static, single reality (Israel et al., 1998; Matsunaga et al., 1996). In reaction to this, minority communities have developed a distrust of research and researchers and a growing reluctance to participate in research. Reasons why many Native Hawaiians are distrustful of traditional research include:

- We are always the guinea pigs.

- We are good enough to study but not good enough to cure.

- Most researchers just "hit and run.” They do not care about us.

- Reputations of researchers were made on our misfortunes.

- We have seen ethical misconduct.

- We have seen research harm individuals and our communities.

- There is no change in our community for having participated.

- There are no tangible benefits for our community

Concerns stem from recognition that they have had little or no input as to research ideas, study design, dissemination, interpretation, or integration of research findings. Local investigators report that Native Hawaiians who have participated in research felt they were "used as guinea pigs" and exploited to advance the researcher's career (Matsunaga et al., 1996; Santos et al., 2001). Additionally, research on minority communities is criticized because it has not addressed the concerns of the group, has been conducted in culturally inappropriate ways, and is not perceived by the group under study as beneficial. In fact, findings may be considered harmful through a failure to share financial or professional profit with the community or by attaching a stigma or notoriety to the group (Green \& Mercer, 2001; Israel et al., 1998; 2001; Matsunaga et al., 1996; Santos et al., 2001).

Researchers who wish to study health issues in minority communities, in both relevant and respectful ways, can overcome many barriers by 
using a community-based participatory research (CBPR) model to conduct their studies. Instead of adhering to a positivist paradigm, a nontraditional paradigm can be adopted through which researchers have a transactional and interactive relationship with study participants and their respective communities. Findings are not objective, but are mediated by values, since reality is influenced by social, political, economic, cultural, ethnic, and gender factors that change over time (Israel et al., 1998). The principles of CBPR would result in research that: a) addresses the health of the community within the broader cultural, social, economic, and political context; b) involves the community at all levels, from priority setting and planning to interpretation and dissemination of findings; c) identifies community needs and concerns that need to be addressed; d) builds on the strengths and resources within the community; e) promotes co-learning and knowledge transfer; f) provides tangible benefits to the community; and g) does no harm (DeCambra \& Enos, 1991; Goodare \& Lockwood, 1999; Goodman, 1998; Green \& Mercer, 2001; Israel et al., 1998; 2001; Macaulay et al., 1998; Matsunaga et al., 1996; Minkler, Fadem, Parry, Blum, Moore, \& Rogers, 2002; Santos et al., 2001).

The coexistence of current health deficiencies in Native Hawaiians and growing resistance to positivist-style health research suggests a need for effectively implemented CBPR. Positive results associated with CBPR were demonstrated in the Wai'anae Cancer Research Project, an NCI-funded study done in collaboration with the Native Hawaiian community. The effects of involving Native Hawaiian community members in research planning, implementation, evaluation, and dissemination of results included increased cancer screenings among the Native Hawaiian population under study, as well as improved health services. Beyond immediate health benefits, the surrounding community also was enriched in knowledge, skills, experience, and resources, both intellectual and financial (Banner et al., 1995; Gotay et al., 2000; Macaulay et al., 1999; Matsunaga et al., 1996).

This paper describes 'Imi Hale-the Native Hawaiian Cancer Awareness, Research and
Training Network and its efforts to relieve the burden of cancer through culturally relevant research that involves community members at all levels, in accordance with the CBPR model. We illustrate challenges and benefits associated with adhering to CBPR principles through summaries of five 'Imi Hale projects. We also present findings from an evaluation of 'Imi Hale's goals, processes, activities, and achievements, as measured by the 2002 annual survey administered to 'Imi Hale advisory board members.

\section{Intervention}

'Imi Hale, the Native Hawaiian Cancer Awareness, Research and Training Network was established in April 2000 as a Special Population Network (SPN) funded by NCI. In response to a national movement to address racial disparities specifically in cancer, the creation of SPN programs was part of an effort to establish a robust and sustainable infrastructure to promote cancer awareness within minority and medically underserved communities and to launch from these more research and cancer-control activities aimed at specific population subgroups. Of the 18 SPN created by this initiative in 2000, 'Imi Hale is the only SPN administrated by a community-based agency. Objectives of 'Imi Hale include: a) increasing cancer awareness among Native Hawaiians; b) increasing the number of research grants addressing cancer in Native Hawaiians; c) nurturing Native Hawaiian researchers and building their cancer-research skills; d) increasing awareness among Native Hawaiians about cancer clinical trials; and e) establishing a participatory research protocol to support cancer research that is both scientifically rigorous and respectful of Native Hawaiian cultural beliefs, practices, values, and customs (Santos et al., 2001). In keeping with the principles of CBPR, the grant-writing process was led by a team of Native Hawaiian researchers and service providers working in collaboration with representatives from the Native Hawaiian community, with members of the established research community serving as advisors. Once funding was awarded, 'Imi Hale staff introduced the program to the greater Native Hawaiian community and potential 
community partners through face-to-face meetings.

\section{Needs Assessment}

To assure that 'Imi Hale activities responded to community-identified needs and concerns, a number of information-gathering efforts were started. For example, community perceptions about cancer awareness and research were solicited through a survey of 'Imi Hale advisors and key informants from organizations serving Native Hawaiians (Santos et al., 2001), through focus groups with Native Hawaiian cancer survivors (Braun, Mokuau, Hunt, Ka‘ano‘i, \& Gotay, 2002), through surveys of two groups of physicians--primary care physicians and cancer specialists (Ka'ano'i, Braun, Gotay, \& Abrigo, 2002; Ka'ano'i, Braun \& Gotay, in press), and through interactions with the Association of Native Hawaiian Civic Clubs (a non-profit umbrella organization of about 4,000 Native Hawaiians affiliated with 43 individual civic clubs). Findings from these continuing efforts are used to guide awareness and research activities.

\section{Personnel and Advisors}

In accordance with the tenets of CBPR, the infrastructure of 'Imi Hale promotes a partnership between the Native Hawaiian community and the greater scientific community through which bidirectional education and capacity building can take place (see Figure 1). Twelve of 15 (80\%) of the 'Imi Hale management and outreach staff are Native Hawaiian, and they are advised by a Community Council (100\% Native Hawaiian), a Scientific Council (60\% Native Hawaiian), and a Steering Committee (80\% Native Hawaiian). The Community and Scientific Councils respectfully provide advice on the cultural appropriateness and scientific merit of activities, and the Steering Committee helps to establish policy.

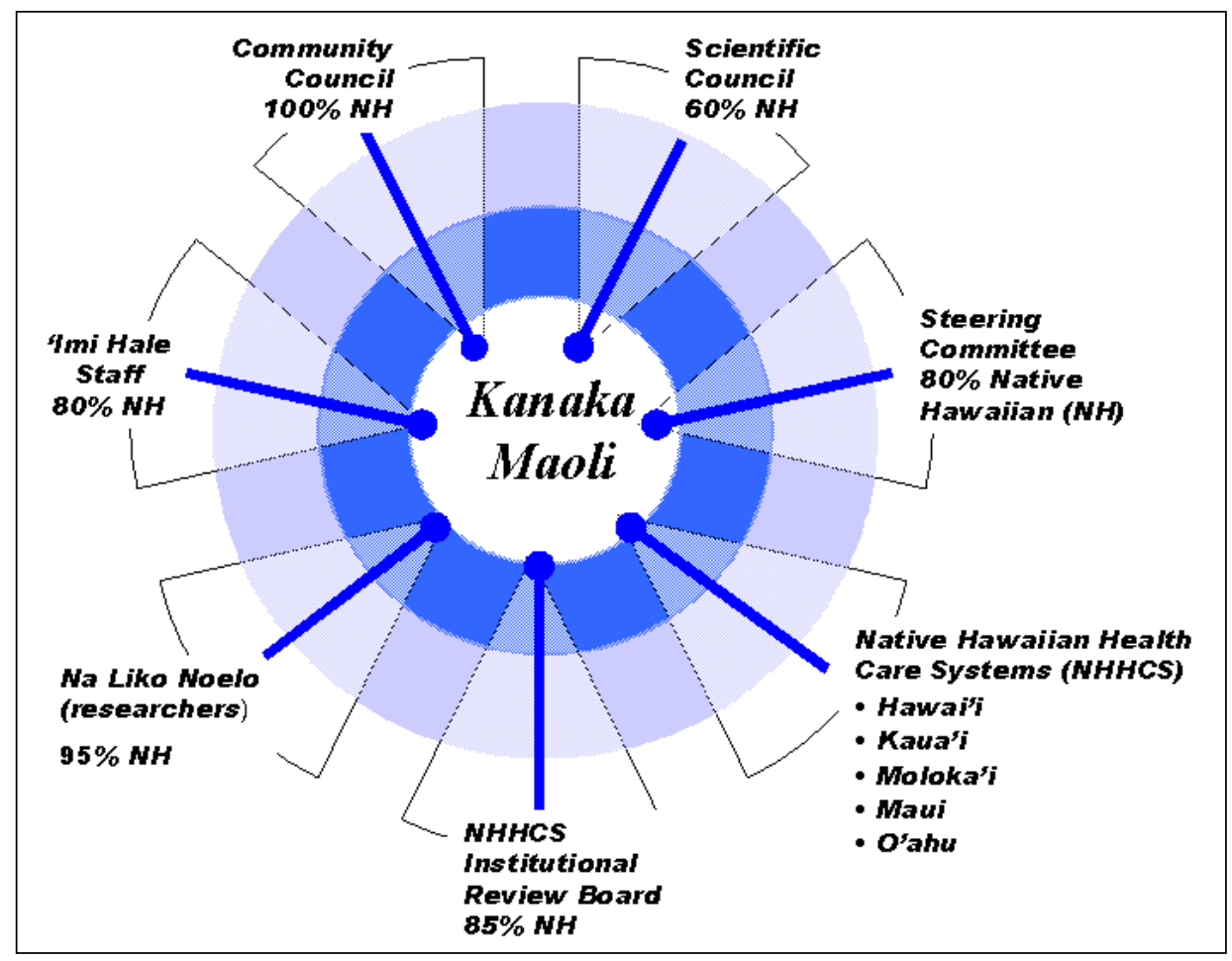

Figure 1

'Imi Hale Infrastructure 
To develop and implement cancer awareness activities, 'Imi Hale works collaboratively with the Native Hawaiian Health Care Systems (NHHCS). The NHHCS includes five community- based entities (one each on the islands of Hawai'i, Kaua'i, Maui, Moloka'i, and O`ahu) that provide health promotion and disease prevention services, such as screenings for chronic diseases, nutritional programs, client support, and advocacy to address barriers to accessing primary care services. In total, NHHCS provides services to more than 25,000 Native Hawaiian clients annually throughout the state. 'Imi Hale contracts with each system for a part-time (40\% FTE) outreach staff, responsible for spearheading cancer awareness activities in his/her island community. They participate in establishing cancer awareness priorities, strategic planning, and program implementation. The Executive Director from each NHHCS serves on the project's Institutional Review Board (IRB), adding their community perspective to the research review process. Executive Directors also serve on 'Imi Hale's Steering committee, adding multi- island community perspective to program policy.

\section{Native Research Program}

The Na Liko Noelo ("budding" native researchers) program identifies and supports Native Hawaiian individuals who want to become cancer researchers and/or learn more about cancer research. In doing so, 'Imi Hale is able to build a network of competent researchers, many of whom already have a trust relationship with the community they are studying. Currently, the program includes over 64 na liko noelo with varied educational backgrounds, from high school students to doctorally prepared individuals, including physicians. Na liko noelo are placed on a listserve and mailing list through which they are alerted to a variety of training and funding opportunities in the area of cancer prevention and control. 'Imi Hale organizes several training programs itself, including annual symposia and multiple-day workshops in research methods, grant writing, and manuscript preparation. $\mathrm{Na}$ liko noelo receive encouragement and can apply for financial assistance to attend cancer research conferences and courses on the continental US. Several were involved in initial studies to determine research priorities and awareness needs in the Native Hawaiian community. Those ready to propose their own studies are assisted by the Research Director and other researchers who, through interagency memoranda, agree to serve as mentors. As an SPN, 'Imi Hale is eligible to compete each year for $\$ 50,000$ supplements from NCI to support research projects proposed by junior researchers. As native peoples, na liko noelo also may apply for pilot-project funds through the Native Researchers Training Program of the Oregon Health and Sciences University (also NCI funded). To date, 19 research projects have been funded, and four more are under review (Table 1). A process is in place to facilitate constant dialogue among na liko noelo, their mentors, and 'Imi Hale advisors to assure that each project addresses community priorities, adheres to cultural protocol, is scientifically sound, and has broad-based support.

\section{Partnerships}

Beyond the internal infrastructure of the 'Imi Hale program, 19 external community and scientific organizations have committed to a partnership with 'Imi Hale, with the goal of increasing Native Hawaiian access to services, training, mentorship opportunities, and technical assistance. Representatives from these agencies offer a variety of perspectives to help assure that 'Imi Hale activities address health within the broader cultural, social, economic, and political context. Based on the notions of equal partnerships and shared power, members of the Native Hawaiian and scientific communities educate each other on their perspectives with a goal of overcoming mutual distrust and improving the quality and usefulness of research. 
Table 1

Funded Research Projects 2000-2003

\begin{tabular}{|l}
\hline NCI-funding pilot projects through SPN mechanism \\
- Breast Cancer Histology \\
- Bioactive Compounds in Hawaiian Medicinal Plants \\
- Colorectal Cancer Screening Intervention \\
- Using Ho‘oponopono to Cope with Cancer Diagnosis and Treatment \\
- Intervention for Families of Women with Breast Cancer \\
- A Program to Decrease Tobacco Use \\
- Comparison of Cilia Motility as a Possible Factor in Lung Cancer \\
- Exercise and Nutrition Education in an After-School Program \\
NCI-funded pilot projects through Oregon Health \& Sciences Native Researchers Cancer Control \\
Training Program \\
- Cultural Expressions of Cancer Pain \\
- Cancer Survivors Address Spirituality \\
- Ten-Year Study of Knowledge, Attitudes, Practices re: Cancer Screening \\
- Maui - Breast Cancer Screening Evaluation \\
- Moloka'i 'Ohana Day Cancer Education \\
- Preferences for Consent for Research on Stored Biological Samples \\
- Healthy Lifestyles for Native Hawaiian Adolescents \\
Other projects \\
- Warrior Diet \\
- Health Practices of Native Hawaiian Men \\
- Colorectal Cancer Awareness Study \\
- Native Hawaiian Tobacco Survey
\end{tabular}

\section{Institutional Review Board (IRB)}

With the establishment of 'Imi Hale and the anticipated increase of research within the Native Hawaiian community, the Native Hawaiian Health Care System formed its own IRB, with representatives from scientific and non-scientific sectors and Hawaiian communities across the state (85\% of members are Native Hawaiian). As mandated by federal law, the goal of this IRB is to ensure ethical conduct of research and to protect the safety of research participants and their respective communities. In doing so, the Native Hawaiian IRB seeks to offer community and cultural perspectives that are lacking in other IRBs, an objective that is critical in light of the distrust by Native Hawaiians of researchers and the research process. The IRB recognizes that, despite past wrongs, research focused on improving health programs is valuable for Native Hawaiian communities. Thus this body also serves as a mechanism for increasing knowledge about and involvement in research among Native Hawaiians.

\section{Evaluation}

Qualitative and quantitative methods are used in the ongoing evaluation of this CBPR program. For example, 'Imi Hale conducts a biennial survey of advisors' perceptions of their control and involvement in 'Imi Hale using a questionnaire adapted from the Detroit Community-Academic Urban Research Center Board (Lantz, Viruell-Fuentes, Israel, Softley, \& 
Guzman, 2001). In 2002, responses were received from $26(87 \%)$ of 'Imi Hale's 30 advisors. The survey included 20 items rated on a 5-point Likert scale measuring advisors' perceptions of general satisfaction, impact, and trust. Items and responses are shown in Table 2.

Table 2

Number (Percent) of Advisors that Agreed or Strongly Agreed with Each Item ( $N=26)$

\begin{tabular}{|l|l|}
\hline \multicolumn{1}{|c|}{ Domain and Item } & N (\%) \\
\hline General Satisfaction & \\
\hline $\begin{array}{l}\text { I am generally satisfied with the activities and progress of 'Imi Hale during the past } \\
\text { year. }\end{array}$ & 24 (92) \\
\hline I generally feel that my mana'o (contribution) is heard and taken seriously. & 24 (92) \\
\hline $\begin{array}{l}\text { I am satisfied with the types of research proposals that have been submitted to 'Imi } \\
\text { Hale. }\end{array}$ & 23 (88) \\
\hline I am satisfied with the types of projects that 'Imi Hale has implemented. & $22(85)$ \\
\hline Thus far, 'Imi Hale has distributed available resources in a fair and equitable manner. & $23(88)$ \\
\hline I would like to have more input into 'Imi Hale's decisions. & $7(27)$ \\
\hline Impact & \\
\hline 'Imi Hale has been effective in achieving its goals. & $24(92)$ \\
\hline 'Imi Hale can have a positive effect on the community. & $24(92)$ \\
\hline I have increased my knowledge of community-based research during the past year. & $21(81)$ \\
\hline Participation in 'Imi Hale has increased my knowledge of other cancer organizations. & $19(73)$ \\
\hline I have increased my knowledge about cancer during the past year. & $22(85)$ \\
\hline 'Imi Hale involves people from all of the major Hawaiian islands in its work. & $23(88)$ \\
\hline 'Imi Hale increases cancer awareness in Native Hawaiian communities. & $21(81)$ \\
\hline 'Imi Hale increases awareness in Native Hawaiian communities of cancer clinical trials. & $14(54)$ \\
\hline 'Imi Hale identifies and nurtures Native Hawaiian researchers. & $23(88)$ \\
\hline 'Imi Hale increases the number of grants that address cancer in Native Hawaiians. & 21 (82) \\
\hline $\begin{array}{l}\text { 'Imi Hale promotes scientifically rigorous research that is culturally appropriate and } \\
\text { respectful of Native Hawaiian cultural beliefs, practices, and customs. }\end{array}$ & 24 (92) \\
\hline Trust & \\
\hline Diverse opinions are allowed and respected at 'Imi Hale meetings. & $26(100)$ \\
\hline I am comfortable expressing my point of view at 'Imi Hale meetings. & $25(96)$ \\
\hline 'Imi Hale is following its own community-based research principles in its activities. & $25(96)$ \\
\hline
\end{tabular}

In general, 'Imi Hale advisors expressed strong or general agreement toward positively worded statements and expressed disagreement or neutrality toward negatively worded statements related to satisfaction, impact, and trust. For example, $92 \%$ were generally satisfied with the activities, $88 \%$ felt resources were distributed in a fair and equitable manner, and 100\% felt that diverse opinions were allowed and respected at meetings. In terms of research, 92\% felt that 'Imi Hale was promoting scientifically rigorous research that was culturally appropriate and respectful of Native Hawaiian beliefs, and 96\% felt that 'Imi Hale was following its own CBPR principles in its activities. However, 27\% indicated that they would like to have more input into decisions, These data suggest a generally high level of satisfaction with 'Imi Hale, but also suggest that more effort needed to be made to allow all voices to be heard.

In addition, a descriptive case-study approach is used to document how researcher and community objectives are balanced within each 
research project. We present excerpts from case studies of five research projects, highlighting challenges and benefits associated with our commitment to the CBPR approach.

\section{Physicians' Knowledge, Attitudes, and Practices Related to Cancer Clinical Trials}

As part of the needs assessment process, surveys of oncologists and primary care physicians were conducted to investigate the underrepresentation of Native Hawaiians in clinical trials, both for cancer treatment and cancer prevention (Ka'ano'i et al., 2002; Ka'ano'i et al., in press).

Findings suggested a need for education and systems changes to help overcome cultural and logistical barriers to Native Hawaiian participation in clinical trials.

This study is an example of a CBPR project with few challenges to overcome. It was designed and directed by a Native Hawaiian physician. Participants came from the medical community, not from a vulnerable population, and items on the questionnaire were straightforward and nonthreatening. Thus, no ethical issues or concerns about human subject protection were raised, and the project was approved as proposed to the NHHCS-IRB. However, the process by which it was conducted yielded a number of benefits. Specifically, the Native Hawaiian physician conducting this project learned more about the survey research process, data analysis, and manuscript preparation. Physicians participating in the survey became aware of a growing interest among Native Hawaiians in cancer screening, treatment, and clinical trials. Finally, Steering Committee and Council members became more familiar with issues related to clinical trials, which they applied to concurrent discussions about prevention trials such as the Study of Tamoxifen and Raloxifene (STAR) and the Selenium and Vitamin E Cancer Prevention Trial.

\section{The STAR Trial}

An initial goal of 'Imi Hale was to increase accrual of Native Hawaiian women to clinical trials, beginning with the STAR trial. Upon review of the protocol, the NHHCS-IRB had a number of questions about side effects associated with tamoxifen and raloxifene. Based on a review of the scientific literature conducted by an IRB member, it appeared that Native Hawaiian women who might be eligible for the trial could be more likely to have co-morbid conditions that would increase their risks for negative side effects from these drugs. Although the principle investigator brought evidence about the safety of the STAR trial to the NHHCS-IRB, two factions developed, and differences became irreconcilable.

'Imi Hale staff and advisors revisited their initial goal to increase accrual and, with the support of NCI, decided to modify it. Instead of committing to recruiting Native Hawaiian women to trials, it was agreed that 'Imi Hale should limit its responsibility to increasing awareness about clinical trials by providing community and physician education. Subsequently, focus groups with Native Hawaiian cancer survivors revealed that few were familiar with the concept of clinical trials, and only two had been informed about them when making treatment decisions. A survey of cancer-specialty physicians suggested that local oncologists were supportive of clinical trials, but they identified a number of barriers to increasing the number of patients on clinical trials in Hawai' $i$, including systems barriers. These findings validated 'Imi Hale's move to modify the initial goal, although the principle investigator was disappointed with this apparent withdrawal of support for STAR. This experience demonstrated how CBPR could present obstacles to established researchers. This experience also demonstrated the need for the community's perspective regarding recruitment for clinical trials and the larger need for community education about clinical trials.

\section{Cancer Survivor Focus Groups}

Focus groups were held on five islands with Native Hawaiian cancer survivors to examine supports and barriers to survival, experiences with clinical trials, and recommendations for future activities to be undertaken by 'Imi Hale (Braun et al., 2002). Following CBPR principles, focus group questions were developed based on community input, and Native Hawaiian outreach workers and na liko noelo were trained as focus group co-facilitators 
and recorders. Outreach workers recruited participants, and their respective NHHCS were compensated for hosting the focus groups. Native Hawaiian cultural protocol was followed in conducting the focus groups, and focus group participants were reconvened to assist in the interpretation of the data. Findings were well received, and the entire process appeared to have an empowering effect on participants, na liko noelo, and 'Imi Hale advisors and partners.

While seemingly straightforward, the study was not approved immediately by the NHHCS-IRB. Rather, the IRB required that two Native Hawaiian professionals be available for counseling and support to all focus group participants for one year following the study. This mandate increased the project's budget and the amount of time needed to complete the work. However, the additional protections put in place reflected IRB concerns about causing harm to focus group participants by asking them to retell their cancer experience to the group. Meeting this requirement also provided the opportunity to involve two more Native Hawaiians in the research process, and both continue with 'Imi Hale as na liko noelo.

\section{Colorectal Cancer Screening Intervention}

In 2001, four na liko noelo conducted a preliminary study with 56 Hawaii-based civic club members, using focus group and survey methodology to examine CRC knowledge, attitudes, and behaviors. Only $12 \%$ of participating civic club members reported compliance with screening recommendations. Findings also indicated a lack of knowledge about CRC and multiple barriers to screening, including lack of insurance, lack of awareness, inconvenience, procrastination, perceived discomfort, and fear of finding cancer. When asked about their willingness to participate in CRC screening, $72 \%$ said that they would participate if the tests were offered at no cost, and $75 \%$ would participate if urged to by Native Hawaiian physicians and CRC survivors. These findings led to design and funding of a proposal to test a culturally appropriate intervention to improve colorectal cancer screening rates among Native Hawaiian civic club members.
'Imi Hale advisors and IRB members were concerned that lack of a primary care physician and lack of insurance would present barriers to screening. Thus, the researchers were required to develop protocols to identify participants without insurance and personal physicians and link them immediately to the 'Imi Hale-funded outreach worker on their island for assistance with enrolling in Medicaid and establishing a relationship with a Native Hawaiian physician in their community. Of the 191 participants that ultimately enrolled in this research project, ten needed (and received) assistance. Developing the protocol delayed the start of the research project by a few months. However, it set a standard for research in the Hawaiian community that draws attention to and takes action to resolve lack of access of some Native Hawaiians to health care providers and coverage.

\section{Comparing Breast Cancer Histology Across Ethnic Groups}

This study was proposed by a Native Hawaiian oncologist who wanted to investigate the effect of tumor aggressiveness, as operationalized by the presence of genetic biomarkers on stage of diagnosis and outcomes of breast cancer patients in five ethnic groups. The study proposed to test archived breast cancer tissue removed from women diagnosed in 1995 and banked in a newly established tissue repository. The investigator would receive de-identified data, i.e., data without names and social security numbers, but each record would include descriptors, including ethnicity.

Members of the Native Hawaiian IRB saw the potential benefits of this research for Native Hawaiians and approved the study on the condition that the investigator obtain informed consent for each woman, either from the patient herself or, if deceased, from her next-of-kin. The IRB cited the Belmont Report's principle of "respect for individuals" when requiring consent, arguing that women who had tissue removed in 1995 did not know their tissue might someday be used in research and that they had a right to know this and make a decision to be included or not. The IRB also cited the principle of "justice" when it expressed concerns about 
the possible negative effect of the study on Native Hawaiians as a group, specifically that Native Hawaiians may be rendered uninsurable if the research found that Native Hawaiian women had more aggressive tumors than women of other ethnic groups.

Another IRB, however, had oversight for the tissue bank and did not approve the consent protocol. Rather, its members believed that the investigator would create unnecessary risk in contacting the patients. These women were not going to be asked for additional information nor provided with the findings from the retesting of their tissue. Because the investigator would receive de-identified data, there was no need to gain access to the identities of the women in this cohort. In fact, contacting the women could jeopardize confidentiality, especially for women who may have kept their diagnosis a secret, and could cause harm by imposing upon women to relive their cancer experience.

The Native Hawaiian IRB and researchers then reviewed state laws and federal regulations that govern IRBs and tissue repositories and investigated the policies on genetic research adopted by other indigenous groups, such as Native American tribes. After lengthy deliberation, it agreed to amend its decision by waiving the requirement for consent. This decision was made in accordance with the Belmont Report's principle of "beneficence," given that the benefits of the research for the Native Hawaiian community were clearly significant. Also, the Native Hawaiian IRB realized that if informed consent for this type of research would not be required by other IRBs, then there would be no stopping another group from proposing and conducting the same study. Given this scenario, the Native Hawaiian IRB saw advantages to having this study conducted by Native Hawaiian investigators. Despite this approval, the project was not pursued because of funding and logistical constraints at the tissue repository. The process demonstrated, however, the challenges presented by CBPR in reconciling competing demands of multiple institutions and the need for a more critical investigation of the potential positive and negative impacts of genetic research on native peoples.

\section{Discussion}

Although 'Imi Hale advisors are generally pleased with the program, CBPR demands continuous assessment of needs, concerns, and issues of power and control, followed by the appropriate course corrections and improvements. The commitment to CBPR presents challenges, which are time-consuming.

All parties are enriched, however, when they successfully work through these issues. The benefits for 'Imi Hale are clear; Native Hawaiians are engaged in research as equals, and communities can see that their interests are being represented and respected.

If data on the health status of minority populations are not available for study, understanding the diseases and contributing factors within these populations will become difficult, if not impossible. This in turn may preclude creation of relevant public health policy and allocation of necessary resources to the community in question (Williams \& Collins, 1995). Given the grave health problems currently facing Native Hawaiians and similar minority groups, it is obvious that the obstacles to conducting research within minority communities must somehow be overcome. CBPR can help build a minority capacity for research, balance researcher and community objectives, and assure that research is conducted in culturally appropriate ways.

\section{References}

Banner, R. O., DeCambra, H., Enos, R., Gotay, C. C., Hammond, O. W., Hedlund, N., et al. (1995). A breast and cervical cancer project in a Native Hawaiian community: Wai 'anae cancer research project. Preventive Medicine, 24, 447-453.

Blaisdell, R. K. (1993). The health status of Kanaka Maoli (Indigenous Hawaiians). Asian American and Pacific Islander Journal of Health, 1, 116-160. 
Blaisdell, R. K. (1998). Culture and cancer in Kanaka Maoli (Native Hawaiians). Asian American and Pacific Islander Journal of Health, 6, 400.

Braun, K. L., Look, M. A., \& Tsark, J. U. (1995). High mortality rates in Native Hawaiians. Hawai‘i Medical Journal, 54, 723-729.

Braun, K. L., Mokuau, N., Hunt, G. H., Ka'ano‘i, M., \& Gotay, C. C. (2002). Supports and obstacles to cancer survival for Hawai 'i’s native people. Cancer Practice, 10(4), 192-200.

Braun, K. L., Yang, H., Onaka, A. T., \& Horiuchi, B. Y. (1996). Life and death in Hawai'ii: Ethnic variations in life expectancy and mortality, 1980 and 1990. Hawai'i Medical Journal, 55, 278283, 302.

Chen, M. S. (1993). A 1993 status report on the health status of Asian Pacific Islander Americans: Comparisons with Health People 2000 objectives. Asian American and Pacific Islander Journal of Health, 1(1), 37-55.

DeCambra, H., \& Enos, R. (May 1991). Principles and criteria of participatory research. Paper presented at the Hawai'i Public Health Association Conference, Honolulu, HI.

Goodare, H., \& Lockwood, S. (1999). Involving patients in clinical research. British Medical Journal, 319, 724-725.

Goodman, R. M. (1998). Principles and tools for evaluating community-based prevention and health promotion programs. Journal of Public Health Management and Practice, 4(2), 37-47.

Gotay, C. C., Muraoka, M., \& Holup, J. (2001). Cultural aspects of cancer prevention and control. In S.S. Kazarian \& D.R. Evans (Eds.). Handbook of Cultural Health Psychology (pp. 163-193). NY: Academic Press.

Gotay, C. C., Banner, R. O., Matsunaga, D. S., Hedlund, N., Enos, R., Issell, B. F., et al. (2000). Impact of a culturally appropriate intervention on breast and cervical screening among Native Hawaiian women. Preventive Medicine, 31, 529-537.

Green, L. W., \& Mercer, S. L. (2001). Can public health researchers and agencies reconcile the push from funding bodies and the pull from communities? American Journal of Public Health, 91, 19261929.

Israel, B. A., Schulz, A. J., Parker, E. A., Becker, A. B. (1998). Review of community-based research: Assessing partnership approaches to improve public health. Annual Review of Public Health, 1998; 19:173-202.

Israel, B. A., Lichtenstein, R., Lantz, P., McGranaghan, R., Allen, A., Guzman, J. R., et al. (2001). The Detroit Community-Academic Urban Research Center: Development, implementation, and evaluation. Journal of Public Health Management and Practice, 7(5), 1-19.

Jones, C. P. (2000). Levels of racism: A theoretic framework and a gardener's tale. American Journal of Public Health, 90, 1212-1215.

Jones, C. P. (2001). Invited commentary: “Race,” racism, and the practice of epidemiology. American Journal of Epidemiology, 154, 299-304.

Ka‘ano‘i, M., Braun, K. L., Gotay, C., \& Abrigo, L. (2002). Oncologists’ knowledge, attitudes and practices related to cancer treatment clinical trials. Hawai'i Medical Journal, 61, 90-94.

Ka‘ano‘i, M., Braun, K. L., \& Gotay, C. (in press). Primary care physicians’ knowledge, attitudes, and practices related to cancer screening and prevention-oriented clinical trials. Pacific Health Dialog.

Lantz, P. M., Viruell-Fuentes, E., Israel, B. A., Softley, D., \& Guzman, R. (2001). Can communities and academia work together on public health research? Evaluation results from a community-based participatory research partnership in Detroit. Journal of Urban Health, 78, 495-507.

Macaulay, A. C., Commanda, L. E., Freeman, W. L., Gibson, N., McCabe, M. L., Robbins, C. M., et al. (November 1998). Responsible research with communities: Participatory research in primary care. Policy statement accepted by North American Primary Care Research Group.

Macaulay, A. C., Commanda, L. E., Freeman, W. L., Gibson, N., McCabe, M. L., Robbins, C. M., et al. (1999). Participatory research maximizes community and lay involvement. British Medical Journal, 319, 774-778. 
Matsunaga, D. S., Enos, R., Gotay, C. C., Banner, R. O., DeCambra, H., Hammond, O. W., et al. (1996). Participatory research in a Native Hawaiian community: The Wai'anae cancer research project. Cancer, 78, 1582-1586.

Miller, B. A., Kolonel, L. N., Bernstein, L., Young, J. L., Swanson, G. M., West, D., et al. (Eds.) (1996). Racial/ethnic patterns of cancer in the United States 1988-1992, NIH Pub. No. 96-4104. Bethesda, MD: National Cancer Institute.

Minkler, M., Fadem, P., Perry, M., Blum, K., Moore, L., \& Rogers, J. (2002). Ethical dilemmas in participatory action research: A case study from the disability community. Health Education and Behavior, 29, 14-29.

Santos, L., Mokuau, N., Abrigo, L., Braun, K. L., Tsark, J. U., Mackura, G., \& Kuahulua, R. (2001). 'Imi Hale: Establishing an inheritance for Native Hawaiians on cancer awareness, research, and training. Pacific Health Dialog, 8(2), 193-202.

Williams, D. R., \& Collins, C. (1995). US socioeconomic and racial differences in health: Patterns and explanations. Annual Review of Sociology, 21, 349-386.

\section{Acknowledgements}

'Imi Hale is funded by a Special Populations Network grant funded by the National Cancer Institute. The investigators are supported by NCI funds awarded to 'Imi Hale, and do not receive other funds that might bias their work. NCI has no role in the design of specific research projects undertaken by 'Imi Hale, in the collection or interpretation of data, or in the writing or submission of manuscripts. All authors have full access to the data and accept full responsibility for its integrity and the accuracy of the analysis. 


\author{
Author Information \\ Megan Fong, BS, Research Associate \\ Imi Hale-Native Hawaiian Cancer Network \\ and Center on Aging, John A. Burns School of Medicine \\ University of Hawai`i at Manoa \\ Kathryn L. Braun, DrPH*, Professor/Director \\ Center on Aging, John A. Burns School of Medicine \\ University of Hawai‘i at Manoa \\ and Research Director, 'Imi Hale-Native Hawaiian Cancer \\ Network \\ Papa Ola Lokahi \\ 894 Queen Street \\ Honolulu, HI 96813 \\ Ph. 808-597-6550 \\ Fax. 808-597-6552 \\ E-Mail: kbraun@hawaii.edu \\ JoAnn Umilani Tsark, MPH, Program Director \\ 'Imi Hale - Native Hawaiian Cancer Network \\ * corresponding author
}

